\title{
A COMPARATIVE APPROACH TO ANTERIOR SEGMENT DYSGENESIS
}

\author{
D. L. WILLIAMS \\ London
}

\section{SUMMARY}

The role of animal models in our developing understanding of anterior segment dysgenesis is outlined. Research in avian models shows the importance of the neural crest in the development of the anterior segment and the failure of terms such as anterior segment cleavage adequately to describe the embryology of this area. Study of the anatomical differences between the anterior segment of the primate and that of the sub-primate mammal explains the differences seen in the dysplastic changes occurring in the iridocorneal angle in man and those occurring in sub-primate mammals such as the rabbit or the dog. Such work gives an improved understanding of congenital lesions seen ophthalmologically in man as well as those encountered in veterinary ophthalmology.

The last 15 years have seen an upsurge of knowledge concerning the embryological origins of the craniofacial region, including the eye. These new insights into the normal and abnormal patterns of craniofacial development have inevitably overturned and refined cherished theories concerning the embryology of specific structures in this area. Nowhere has this been more obvious than in the anterior segment of the eye, where theories of mesodermal cleavage have been definitively demonstrated to be totally incorrect. Mesoderm is clearly not involved in the establishment of the anterior segment, which is almost completely derived from neurectoderm and neural crest. There is no cleavage: sequential migration of waves of neural crest cells establishes the corneal endothelium and stroma, iris, and angle.

We now understand the embryological origins of the anterior segment development, but are by no means out of the trees with regard to a comprehensive appreciation of the genesis of the wide range of congenital, and indeed later onset abnormalities of the corneal endothelium, iris

Correspondence to: D. L. Williams, MA, VetMB, CertVOphthal, MRCVS, Royal Veterinary College, Royal College Street, London NW1 0TU, UK. and iridocorneal angle. The vast majority of the embryological analysis has been achieved using chimeras created between chick and quail embryos to enable neural crest cell migration and fate to be followed. We assume that this work can be extrapolated to mammals - but is this really the case? We now know where neural crest cells migrate and to which craniofacial structures they give rise. Two questions persist: what makes them move, and what guides them to their final position? The interplay between morphological determination at the cellular level, the physical environment around these migrating cells and external influences in health and disease have yet to be completely unravelled. The insults which cause abnormalities in development of the anterior segment are very poorly understood in terms of when they act, when their effects are manifest and how they actually affect the complex interactions of developing anterior segment activity.

A comparative approach to these problems will perhaps start to unravel some of the exciting and challenging profusion of abnormalities. The few mammalian models of anterior segment dysgenesis that we have, especially that of keratolenticular dysgenesis, give some remarkable and quite beautiful insights into early developmental problems. Comparisons between man and domestic animals are difficult and dangerous because of anatomical variations between the human and the animal anterior segment and iridocorneal angle. However, there are clearly interesting parallels between human, dog, cat, horse and other species. Conditions for which there are no direct domestic animal counterparts are perhaps even more important since they may signal important developmental aspects of the human and primate eye.

\section{THE HISTORICAL BACKGROUND}

In the first half of this century a large number of separate congenital abnormalities of the anterior segment were reported. This terminology, from posterior embryotoxon to internal corneal ulcer of von Hippel, was uniformly 
confusing and often couched in eponymous rather than descriptive terms. It was not until the 1950s that the 'lumpers' gained precedence over the 'splitters' and the term 'anterior chamber cleavage syndrome' was coined. ${ }^{1}$ This was followed by a more organised classification based on a progression from simple to complex abnormalities. ${ }^{2}$ At this time, more comprehensive analyses of corneal leukomas and their possible aetiologies were described. ${ }^{3-6}$

In the early twentieth century little attention was devoted to a comparative approach to the problem. Notable exceptions to this were Treacher Collins, who described persistent pupillary membrane attachment to the posterior cornea in a cat ${ }^{7}$ and Ida Mann, who amassed a formidable collection of domestic animal developmental abnormalities during her embryological studies. ${ }^{8}$

The great benefits accrued by recognising anterior segment dysgenesis as a spectrum of diseases are balanced by the problems which occur when considering unifying abnormalities, such as Peters' anomaly and the AxenfeldRieger complex, which occur at quite different stages in ocular morphogenesis. Hence, the conceptually valuable step-ladder approach to categorisation ${ }^{2}$ must constantly be subjected to modification and re-appraisal.

In 1975 experimental work demonstrated that neural crest plays a major role in the formation of avian ocular and periocular tissues. ${ }^{9}$ By 1979 the precise contributions of neurectoderm, neural crest and 'true' mesoderm to the eye and its surrounding tissue had been defined in the chick embryo. ${ }^{10}$ Quail cells possess a unique intrinsic and stable marker, the Feulgen-positive nucleolus. This was the key feature which allowed the migration and ultimate fate of quail neural crest transplanted into a chick embryo to be followed. The quail and chick chimeric model showed that three waves of neural crest cells invade the area between the surface ectoderm and the optic cup. These cells give rise to corneal fibroblasts, the corneal endothelium, the anterior iridal stroma, and structures in the iridocorneal angle. Indeed, the only structure which is truly mesodermal in the developing anterior chamber is the vascular bed of the iridopupillary lamina. This persists into the last trimester of pregnancy in humans, and later in other species, anastomosing with the tunica vasculosa lentis.

The enormous extent to which neural crest contributes components of the anterior segment firmly establishes the concept that most anterior segment congenital anomalies, and indeed many abnormalities which are not strictly congenital in presentation, are essentially neurocristopathies. Defects in neural crest contribution may thus result from their defective formation, migration or differentiation. ${ }^{11,12}$ It is only for a few abnormalities that have we any clear idea of the true pathogenesis of the lesion.

It might be more valid to consider collections of linked syndromes as morphological field defects-a set of malformations which are disparate in their origins but linked with regard to their morphological outcome. A given set of abnormalities would thus define an embryological unit, such as in this case ocular neural crest, which reacts uni- formly and consistently to a wide range of different insults. However, 'anterior segment neurocristopathic developmental field defect' seems unlikely to supersede 'anterior segment cleavage syndrome' in ophthalmological cocktail party conversation!

\section{KERATOLENTICULAR DYSGENESIS}

The first of the anterior segment anomalies to occur in the developing embryo is the defect which results in Peters' anomaly or keratolenticular dysgenesis. Histopathological studies of eyes with central leukomas suggested that Peters' anomaly was part of the spectrum of 'mesenchymal dysgenesis', ${ }^{6}$ yet the central nature of the primary lesion is difficult to reconcile with more peripheral defects such as the Axenfeld-Rieger complex. Recent work in a murine model has shown what is happening in this defect quite beautifully.

A murine model of fetal alchohol syndrome (FAS), in which ethanol is administered to the mother on gestation day 7 , gives rise to a number of abnormalities. ${ }^{13}$ The same lesions can be produced with 13-cis-retinoic acid, ${ }^{14}$ ochratoxin $\mathrm{A}^{15}$ or radiation. ${ }^{16}$ Keratolenticular dysgenesis is chief among these abnormalities, others being microphthalmia, persistent pupillary membranes, iris hypoplasia and peripheral iridocorneal attachments. These findings are consistent with the anterior segment defects resulting from FAS in man. ${ }^{17}$ The other more generalised signs of FAS - microencephaly, short upturned nose and long upper lip with absent philtrum - are also seen in this experimental mouse model. ${ }^{18}$ Gestational day 7 is a very early stage to induce such specific ocular changes. At this embryonic stage gastrulation is occurring and the primary effect of the teratogen is on forebrain neural plate size. Soon after gastrulation the optic sulci form as evaginations of the developing forebrain, so the effect could be primarily on the optic primordia. At this same time, the neural crest cell population is also being established and so a primary effect on it cannot be ruled out. Examination of developing eyes on gestational day 12 , when the lens vesicle should be separating from the overlying ectoderm, reveals persistence of a stalk between the lens and contiguous ectoderm. This failure of lens separation would clearly establish a physical barrier to invasion of neural crest cells to form corneal endothelium and fibroblasts, thus giving neural crest a secondary role in the lesion. Quite why such an early insult should prevent keratolenticular separation is not evident. Considerable research on the pattern of cell death in normal detachment of the lens rudiment shows the importance of programmed apoptosis or cell fragmentation and active phagocytosis in the chick ${ }^{19}$ and rat. ${ }^{20}$ However, the mechanisms of separation in the FAS model have been subjected to only limited investigation. Embryos exposed to isoretinoin show reduced staining for fibronectin and laminin in and around the keratolenticular stalk. Later in gestation the stalk stains more intensely with antibodies to laminin than either the normal corneal stroma or the anterior lens capsule. Delayed expression of extracellular matrix compon- 
ents may therefore be responsible for failure of separation. $^{21}$

Both experimentally and clinically, Peters' anomaly can be correlated with a number of causes and concurrent malformations..$^{22,23}$ The association with defects such as Goldenhaar's syndrome, mandibulofacial dystosis and Robert's syndrome with phocomelia is highly suggestive of abnormalities affecting the neural crest component. ${ }^{24}$ Keratolenticular dysgenesis occurs in domestic animals typically in isolation from other craniofacial defects (Fig. 2). Since these defects are isolated findings in individual animals they rarely find their way to an ophthalmologically interested veterinary surgeon or into the veterinary literature. Few ocular anomalies associated with craniofacial anomalies are reported in adult domestic animals, since any animal with a relatively severe congenital defect is likely to be euthanased rather than being studied in detail. It is these animals which would be most likely to display ocular effects in association with major systemic malformations.

In conclusion, experimental Peters' syndrome results from an abnormal interaction between neural crest and ectodermal tissues at the site of the lens stalk. This may be induced by an earlier insult affecting optic primordia and resulting in a failure of keratolenticular separation which, in turn, prevents neural crest cells from establishing endothelium and fibroblasts in the central cornea. A defect affecting ocular neural-crest-derived tissue cannot be eliminated as an additional cause of the lesion.

\section{PERIPHERAL DYSGENESIS}

Many cases of Peters' anomaly also exhibit elements of peripheral anterior segment dysgenesis, but peripheral defects can generally be grouped as the Axenfeld-Rieger syndrome. ${ }^{25}$ Within this group three eponyms cover the spectrum of defects: Axenfeld's anomaly is limited to peripheral defects such as prominent Schwalbe's line with or without strands between iris and cornea; Rieger's anomaly occurs where peripheral anomalies are complicated by iridal changes such as correctopia, iridal stromal atrophy and hole formation; Reiger's syndrome embraces these ocular lesions occurring with non-ocular defects such as hypodontia and periumbilical skin abnormalities. It is in these peripheral anterior segment defects that a comparative approach may be most useful, although few ophthalmologists and researchers have adopted this approach. Paradoxically the value of an investigation of peripheral defects in domestic animals relies on the fact that the anatomy of the iridocorneal angle of 'lower' mammals differs from that of the primates and man.

The anatomy of the human iridocorneal angle and trabecular meshwork is obviously considered as 'normal' by medical ophthalmologists, yet the primate and human angles are not at all representative of most mammalian species. The massive development of the ciliary muscle in the primate has necessitated a rearrangement in which the trabecular meshwork eventually lies anterior to the iridocorneal angle, through a recession of the tissue in the embryonic angle. Yet in the dog, cat and most other 'lower' mammals, the trabecular meshwork lies within the angle itself. The trabeculae occupy the apex of the angle and extend caudally into the ciliary body. Embryologically there is no iris recession to uncover the trabecular meshwork because the trabeculae form by organisation of tissue in the angle itself. In short, the mature angle of the domestic animals resembles that of the early third trimester human embryo. Since abnormalities in human peripheral anterior segment dysgenesis result from maldevelopments in the last 3 months of pregnancy, analogous conditions would not be expected in the dog or cat eye.

The stages of development of the human iridocorneal angle and trabecular meshwork have been studied extensively. ${ }^{26,27}$ At 5 months of gestation the anterior surface of the iris inserts at the limbal edge of the corneal endothelium, covering the area of the putative trabecular meshwork. In older fetuses the peripheral anterior iris face lies progressively further back, most probably because of differential growth, such that at birth the iris inserts near the scleral spur. During the first year of life it moves still further posteriorly. After iris recession, a thin band of tissue, contiguous with the anterior face of the iris and the corneal endothelium, lies across the angle. It has been suggested that this is a multilayered mesenchymal structure, ${ }^{26}$ although other workers consider that it is a true endothelium which ultimately fenestrates to reveal the meshwork during the peripartum period. ${ }^{28}$ An equivalent structure has been shown in the primate eye, ${ }^{29}$ where fenestration of the endothelium occurs from posterior to anterior. The trabecular meshwork develops concurrently with rarefaction by cell death or active dissolution of tissue, most probably progressing from anterior to posterior. ${ }^{30}$ The iris recession uncovers not only the trabecular meshwork but also the line of demarcation between the corneal endothelium and the endothelialised angle: Schwalbe's line. This is the point on the posterior corneal face from which the endothelial sheet leaves the cornea to join the iris across the face of the angle.

In contrast, the development of the canine angle is quite simple. ${ }^{31}$ No iris recession occurs and the pectinate ligament and trabecular meshwork lying at the apex of the iridocorneal angle (Figs. 3 and 5) are uncovered by the rarefaction of a sheet of tissue in the angle, probably analogous to the endothelial sheet described in man and primates. Dissolution to reveal the trabecular meshwork appears to be extremely variable in time course but is complete by approximately 20 days post-partum. Beneath this cell layer is a considerable amount of neural-crest-derived tissue which forms the individual trabeculae. The lack of iris recession also means that the corneal endothelium runs as far peripherally as the pectinate ligament, merging with the bases of its individual pillars (Fig. 5). Hence, there is no equivalent of Schwalbe's line in the nonprimate mammal.

The major differences in the anatomy of the domestic animal and human angles have considerable implications 
for the classification of glaucoma in the former. In nonprimate eyes, terms such as open angle and closed angle glaucoma are not strictly appropriate. However, such consideration and discussion is beyond the scope of this review. In the field of anterior segment developmental abnormalities, the key feature of the morphogenesis of the dog or cat angle is that since there is no iris recession, the morphology of aberrant tissue retained in the angle is different from that in man. This is not to say that defects in the differentiation of the lower mammalian angle do not occur. A number of reports describe anterior segment dysgenesis in the dog. Most of these have been associated with microphthalmos and other severe multiple ocular lesions. ${ }^{31-34}$ A number of reports of anterior segment dysgenesis with microphthalmos and retinal dysplasia in Dobermann pinschers have been published. It appears that all these dogs are related, although they are found in both America and Europe ${ }^{33,35}$-such is the peril of indiscriminate inbreeding! The condition appears to be inherited as an autosomal recessive trait. $^{36}$ These canine anomalies involve lack of development of the angle as well as iris pigmented epithelium and sphincter and dilator muscles. With such major defects, anatomical comparisons between these animals and human anterior segment dysgeneses are difficult.

The currently favoured mechanism of the establishment of the abnormalities associated with human peripheral dysgenesis involves the failure of involution, rarefaction or fenestration of the endothelial layer forming a synechia between the cornea and iris after iris recession. ${ }^{37,38}$ This explains the spectrum of anomalies ranging from merely a prominent Schwalbe's line to extensive retained iridocorneal attachments arising from this area of the cornea. The mechanism of hole formation in the more severe forms of dysgenesis is unclear but may be related to tension from iridocorneal attachments or vascular inadequacy leading to iridal ischaemia. The cause of glaucoma is also uncertain: while it has been suggested that the retained endothelium is a sufficient block to outflow, resulting in a rise in pressure, ${ }^{39}$ it is now generally considered that concurrent trabecular changes in the posterior part of the meshwork, notably proximal insertion of the iris root, are the main factors in outflow obstruction. ${ }^{37,40}$

What of the domestic animals? Do such peripheral anomalies occur? A number of breeds of dog exhibit familial predisposition to glaucoma, and peripheral congenital angle abnormalities can be seen in several of these. However, in these animals the embryonic endothelial covering of the angle blends into the depths of the angle, merging with the pectinate ligament itself. It does not arise from Schwalbe's line stretching from cornea to iris in front of the face of the angle. Hence, in cases of peripheral endothelial retention in the dog, the tissue complex forming in the angle is termed the dysplastic pectinate ligament. Whole bands of tissue sometimes obscure the apex of the angle in gonioscopic examination (Fig. 4). Fenestrations in the centre of these bands may reveal the underlying pectinate ligament of apparently normal appearance. ${ }^{41}$ Thus, dysplastic pectinate ligaments might be analogous to peripheral dysgeneses, given that in both conditions persistence of the endothelial sheet across the angle occurs. In these dogs, such as American and English cocker spaniels, basset hounds and elkhounds, glaucoma occurs in early middle age. Histopathological differences in the morphology of the pectinate ligaments in these different breeds suggest that the formation of these abnormalities may not be identical. As in humans with peripheral dysgeneses, these can prove very difficult to manage clinically.

New Zealand White rabbits with early-onset glaucoma, inherited as a semi-lethal recessive trait, are also an example of congenital persistence of a tissue sheet in the iridocorneal angle. However, in this case failure of differentiation of angle structures is also seen and the whole area of the ciliary cleft appears to be a mass of undifferentiated tissue (Fig. 8). ${ }^{42}$

\section{NON-OCULAR CHANGES IN PERIPHERAL DYSGENESES}

In the human, a large number of apparently associated non-ocular defects have been reported. ${ }^{37,43}$ Dental abnormalities such as microdontia and hypodontia associated with Rieger's syndrome were first reported soon after Rieger's first paper. ${ }^{44}$ Dental anomalies associated with Axenfeld's anomaly have also been reported. ${ }^{45}$ Facial abnormalities such as maxillary hypoplasia, prominent lower lip, hypertelorism and telecanthus have also been noted. ${ }^{38}$ Pituitary defects have resulted in growth hormone deficiency in some patients. Such abnormalities could be linked with neural crest defects, but umbilical defects and hypospadias associated with Axenfeld-Rieger cases are more surprising. ${ }^{46}$

Anterior segment dysgeneses are also seen in other syndromes with multiple non-ocular defects such as velocardio-facial syndrome ${ }^{47}$ and Di-George syndrome. ${ }^{48,49}$ In some cases the involvement of the anterior segment has inferred neural crest involvement in the generation of the ocular and the systemic defects.

\section{IRIDOCORNEAL ENDOTHELIAL SYNDROMES}

Another set of disorders involving the cornea, anterior chamber angle and iris, and manifest as a spectrum of disorders, is the conglomeration of progressive essential iris atrophy, Chandler's syndrome and Cogan-Reese (iris naevus) syndrome. ${ }^{50}$ These patients may present with a distorted pupil, correctopia or dark iris pigmentation. Alternatively they may exhibit visual deficits related to corneal oedema or secondary glaucoma. Gonioscopy reveals peripheral anterior synechiae with a Descemet'slike membrane over the iridocorneal angle. Histologically, Chandler's syndrome corneas include unusually shaped endothelial cells with an acellular fibrous layer on the posterior cornea. The Cogan-Reese variation demonstrates pigmented pedicles on the iris or a matted appearance to the stromal surface, features which are well documented. ${ }^{50}$ 


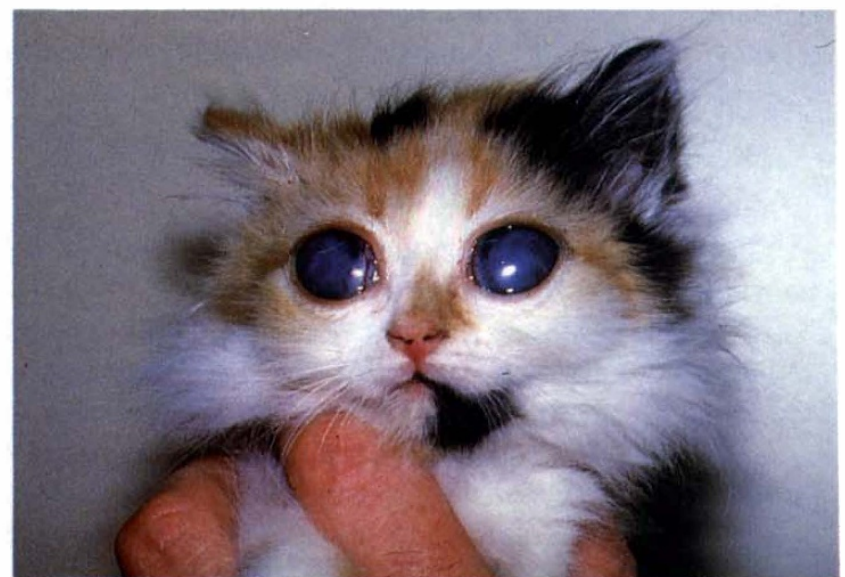

Fig. 1. Congenital glaucoma with buphthalmos in a 9-weekold domestic short-hair cat. (Courtesy of Dr. K. C. Barnett.)

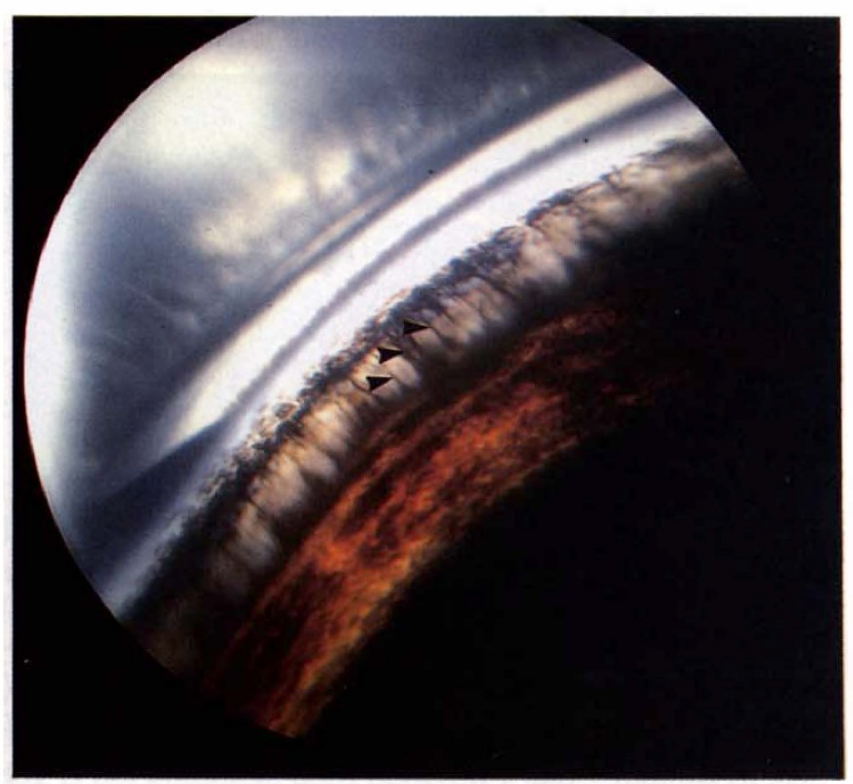

Fig. 3. Goniophotograph of the normal iridocorneal angle of an adult cross-bred dog. The pectinate ligament consisting of individual pectinate fibres (arrowed) can be identified in the iridocorneal angle.

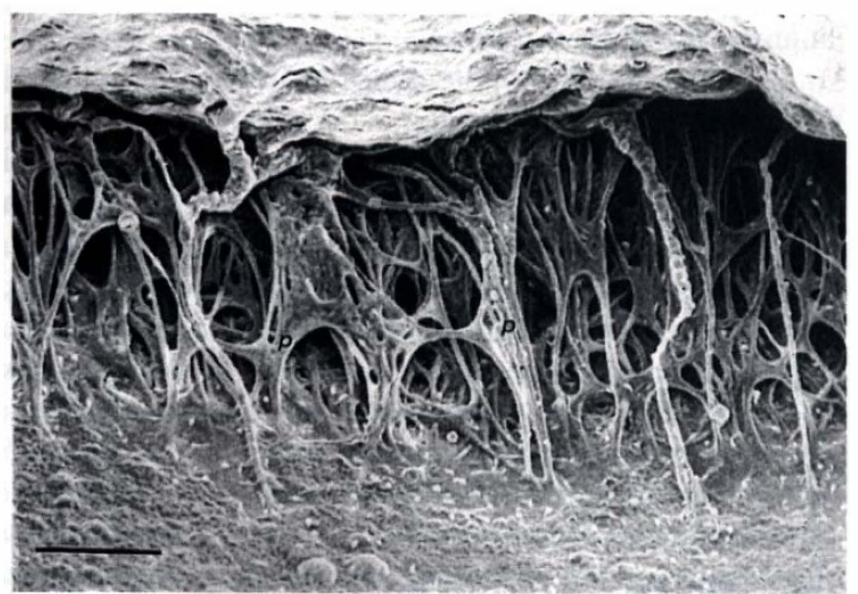

Fig. 5. Scanning electron micrograph of the pectinate ligament of the normal canine iridocorneal angle of an adult crossbred dog. The pectinate fibres $(p)$ are widely separated revealing the fibres of the trabecular meshwork $(t)$ deeper in the iridocorneal angle. Scale bar represents $200 \mu \mathrm{m}$.

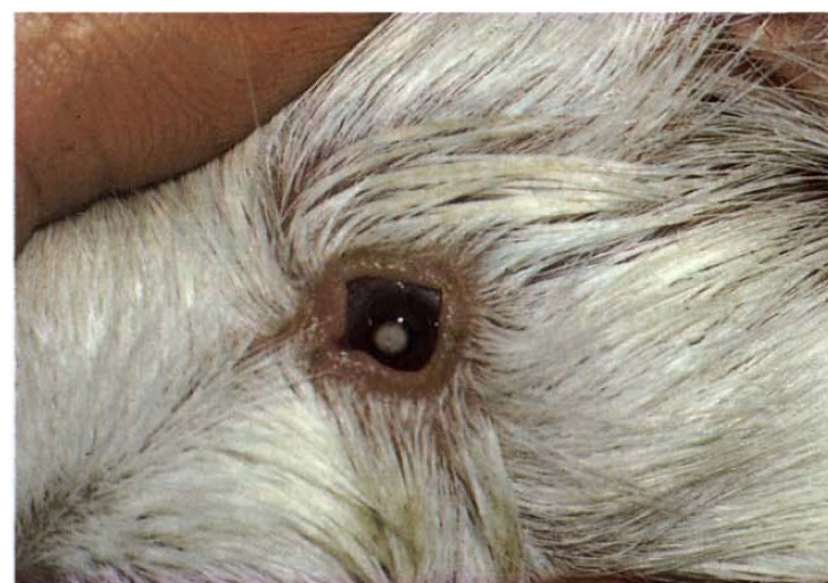

Fig. 2. Congenital central corneal opacity with microphthalmos clinically similar to Peters' anomaly in a guinea pig. (Courtesy of Dr. S. Crispin.)

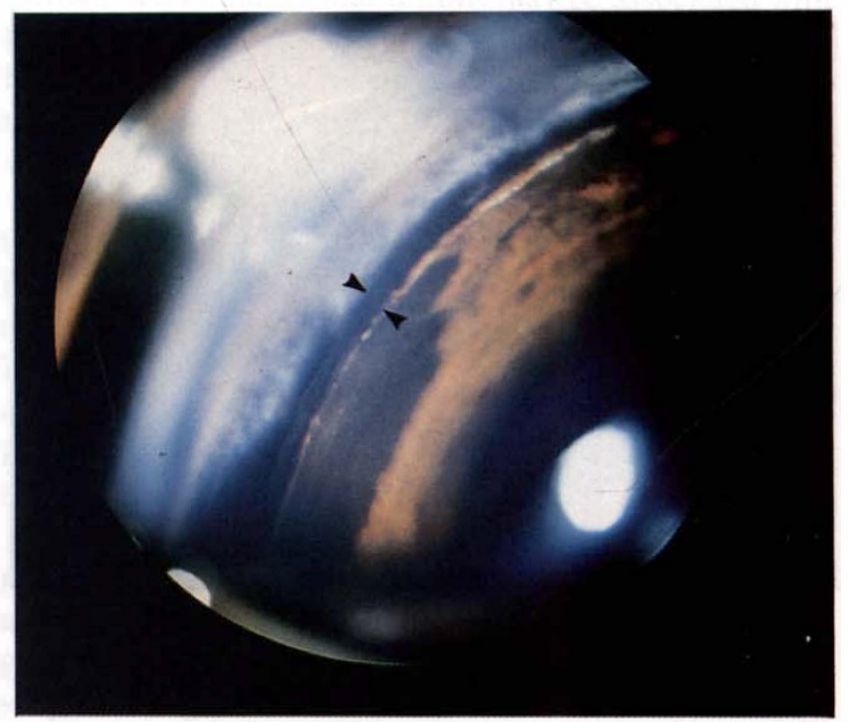

Fig. 4. Goniophotograph of dysplastic pectinate ligament in a golden retriever in which a solid band of tissue is seen (between arrows) in the iridocorneal angle.

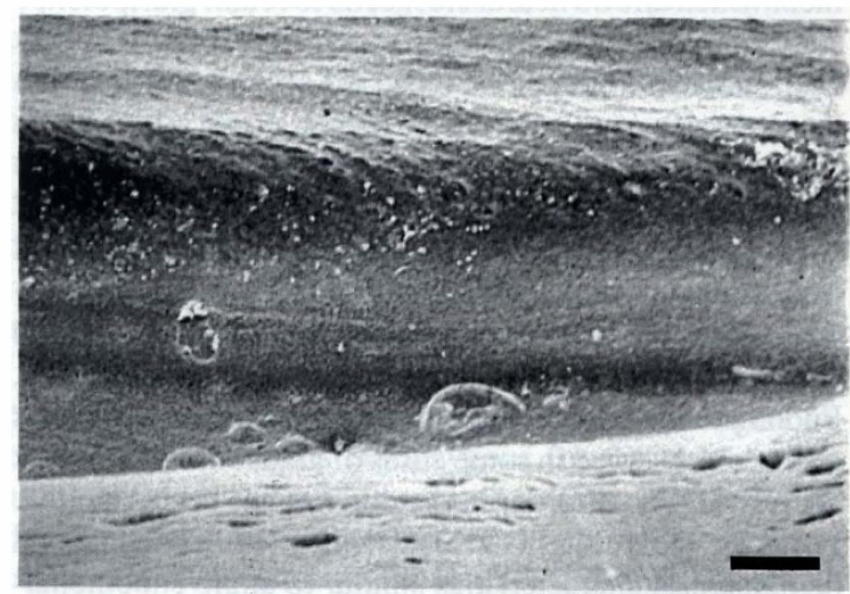

Fig. 6. Scanning electron micrograph of the dysplastic pectinate ligament of a Siberian husky. No trabecular beams are visible since an endothelial sheet overlies the pectinate ligament. Scale bar represents $100 \mu \mathrm{m}$. 


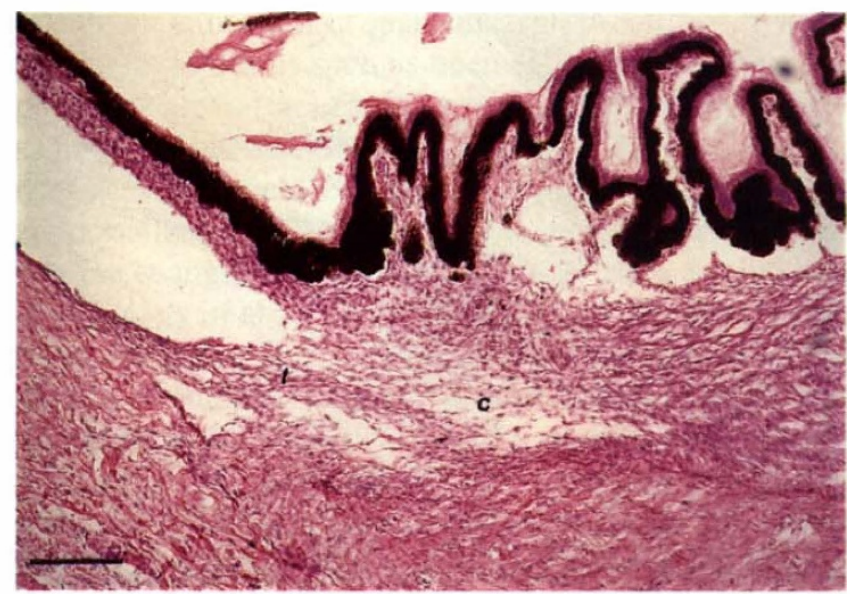

Fig. 7. Histological specimen illustrating the normal iridocorneal angle of rabbit with the trabecular meshwork $(t)$ and ciliary cleft (c) seen posterior to the pectinate ligament in the iridocorneal angle. Scale bar represents $200 \mu \mathrm{m}$.

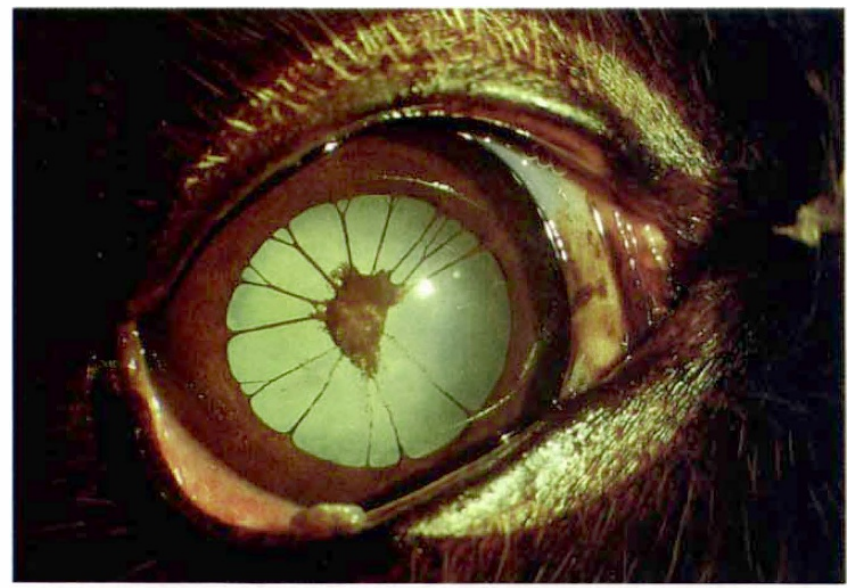

Fig. 9. Persistent pupillary membranes in a cross-bred dog.

The late onset of these conditions may seem initially to preclude a neural crest involvement. However, it has been suggested that there is a late arrest of endothelial development which allows neural crest cells to retain pluripotency and to migrate and divide as epithelial-like cells. ${ }^{6}$ The corneal endothelium appears to be the prime culprit in the development of the lesions in essential iris atrophy: the classification as late-onset neural crest defects is therefore justifiable.

Chandler's syndrome is probably a variant of essential iris atrophy. It involves abnormal proliferation of the corneal endothelium, often late in life, resulting in peripheral anterior synechiae which progressively occlude the angle. Endothelialisation of the canine iridocorneal angle has also been observed'in some cases of glaucoma, but further analysis of this disorder in the dog has not been reported. Posterior polymorphous dystrophy (PPMD) in man demonstrates characteristics similar to angle endothelialisation: differential diagnosis between PPMD and Chandler's syndrome has been described in detail. ${ }^{51} \mathrm{~A}$ PPMD has been reported in the American cocker span-

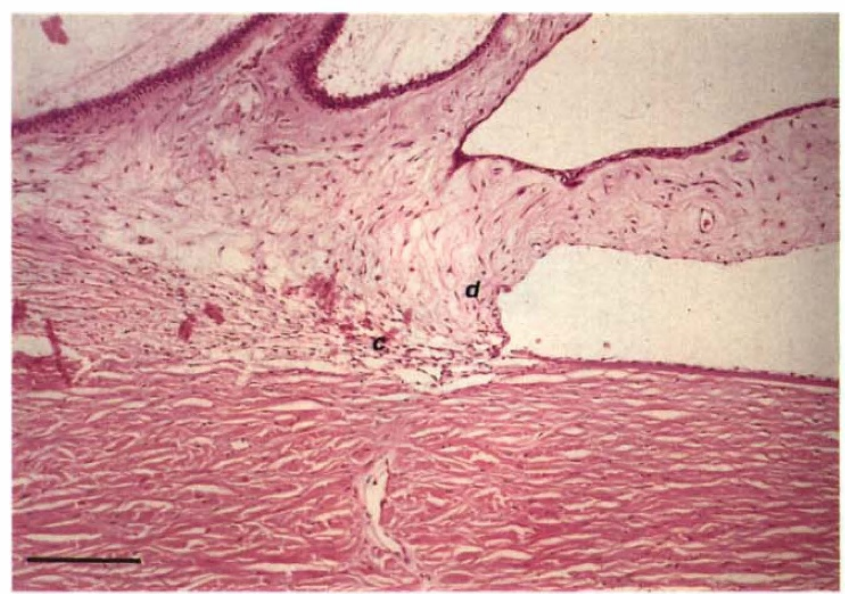

Fig. 8. Pectinate ligament dysplasia in a New Zealand White rabbit. A broad band of persistent dysplastic tissue (d) spans the iridocorneal angle, occluding the area of the ciliary cleft (c), now collapsed. Scale bar represents $200 \mu \mathrm{m}$.

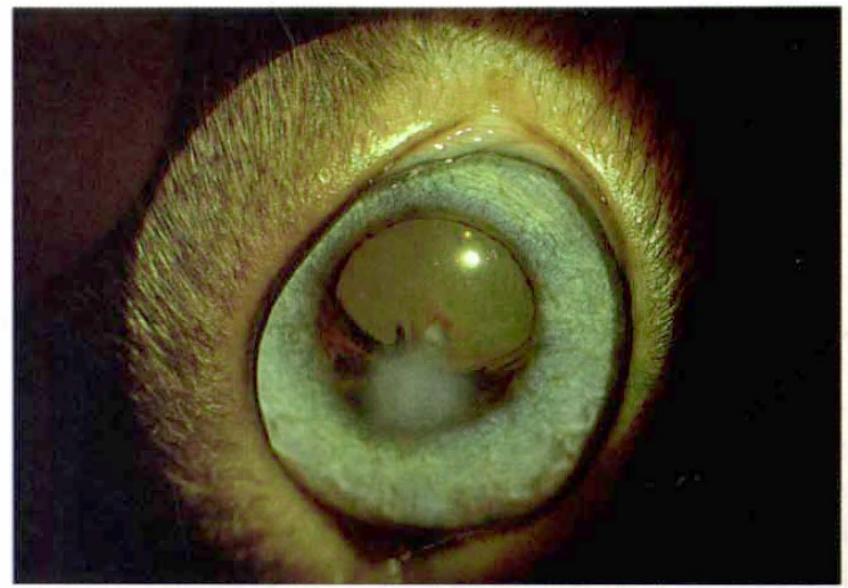

Fig. 10. Axial changes with iridal abnormality, iridocorneal adhesions and corneal opacity consistent with anterior segment dysgenesis in a Burmese cat.

iel ${ }^{52}$ but the term appears to be purely descriptive and does not suggest a similar pathogenesis to PPMD in man. These dogs do not appear to exhibit elevated intraocular pressure at any stage of their disease.

A canine condition potentially analogous to essential iris atrophy has been reported in dachshunds. ${ }^{53-55}$ Dogs in which iridal anomalies were the only obvious clinical problem show non-pigmented iridal stroma, stroma which was easily transilluminated, polycoria and correctopia. More severe defects include microphthalmia, microcoria, correctopia, cataracts and posterior segment colobomas. These changes have been recognised in dogs homozygous or heterozygous for the merle gene (see below). Intraocular pressure in a number of these dogs is increased ${ }^{56}$ and glaucoma has been noted in several. ${ }^{53}$

Morphometric studies of these merle dachshund corneas demonstrated a significantly thicker corneal epithelium. Corneal diameter was also measurably smaller than in non-merle dogs. ${ }^{57}$

Congenital iris ectropion in humans is another member of the neural-crest-derived family of ocular lesions. Con- 
genital iris ectropion has been linked with trabecular dysgenesis and subsequent glaucoma ${ }^{58,59}$ and this link and its implications have been discussed in detail. ${ }^{60}$

\section{OCULAR DYSGENESIS AND THE MERLE GENE}

Persistent pupillary membrane, described in a number of breeds of dog and in other animals, is reported in much higher numbers than persistent pupillary membrane in man (Fig. 9). It might be argued that since the pupillary membranes are not neural crest in origin, persistence of these structures is not a manifestation of anterior segment dysgenesis. Some reports appear to link pupillary membranes with lesions resulting from neural crest abnormalities. However, in defects such as pupil-associated membranes with goniodysgenesis ${ }^{61}$ the membrane does not arise from the minor collarette and thus is presumed to be the result of a localised infarct with secondary neovascularisation during angle formation rather than a neuralcrest-associated defect.

Several syndromes in the dog are included in this review because they have persistent pupillary membrane associated with either maxillofacial defects or clearly defined anterior segment dysgenesis. The most significant of these are associated with the merle gene which regulates pigmentation in a number of breeds of dog. Thus the merle gene may be related to neural crest involvement in ocular development.

The iridopupillary blood vessels lead to the formation of persistent pupillary membranes when they are retained. They are the vascular portion of the iridopupillary lamina and are contiguous with the vascular tunic around the lens. Retention of the posterior part of this tunic is involved in persistent hyperplastic tunica vasculosa lentis and primary vitreous, which is well documented in the Dobermann pinscher dog. ${ }^{62}$ Atrophy of the iridopupillary vessels in the dog is not complete until between 1 and 2 months of age. In some dog breeds, mostly notably Basenji dogs, postpartum retention of these vascular strands occurs frequently. ${ }^{63}$ Similar defects are seen in other animals ${ }^{64}$ and persistent pupillary membranes in association with iridal colobomata in the Basenji have been reported. ${ }^{65}$ While the defects are heritable, no simple dominant or recessive trait can be defined. ${ }^{66}$

Microphthalmos with both anterior subcapsular cataract and persistent pupillary membranes occurs in a number of dog breeds. Some breeds, such as the cocker spaniel, seem to be predisposed to these congenital lesions. Personal observations on the offspring of affected parents and work of other veterinary ophthalmologists ${ }^{67,68}$ indicate that the defect is not inherited in either a simple recessive or dominant manner. Associated dental hypoplasia is also seen in some animals. ${ }^{69}$ An element of intrauterine inflammatory disease has been postulated to be at least partly responsible, because often a large number of puppies in one litter may be affected. However, the pupillary membranes attach to the minor collarette of the anterior iris, not the pupillary margin. They are thus not anterior synechiae secondary to inflammation.
The connection of persistent pupillary membrane with syndromes which definitively involve neurocristopathies is, in all probability, the combination of at least two defects. Although they are embryologically distinct, they occur during the same developmental period. Thus they occur in individuals subjected to insult at a critical stage in the development of both primitive vascular and neural crest structures. An example of such a condition is persistent pupillary membranes in conjunction with multiple ocular colobomata in the snow leopard. A number of snow leopards have upper eyelid colobomata and posterior segment axial colobomata, but in one litter of pups severe bilateral persistent pupillary membranes was noted. ${ }^{70}$ An in utero insult at the critical stage when both the iridopupillary membrane is forming and the embryological fissure is closing might be suggested rather than a direct developmental association between these defects. As their name suggests, snow leopards have reduced coat pigmentation and thus ocular lesions may be associated with this reduction in neural-crest-derived pigment cells. This link between coat colour and neurocristopathies which may involve ocular anomalies, is potentially a very useful spontaneous animal model for these defects.

Coat colour in a diverse range of laboratory animals has been associated with ocular defects and linked to albinism in man. ${ }^{71}$ Albino gene series have been described in a number of pet animals and farm livestock: the acromelanistic Siamese cat is well known to have ocular, auditory and neurological defects, but many other examples exist in domestic animals. ${ }^{72,73}$ These will form the subject of a subsequent comparative review.

As already indicated in the dachshund, the canine merle gene presents some interesting findings with regard to anterior segment morphology. A breed in which the merle gene is associated with ocular defects is the Australian shepherd dog. Coat colour in this breed may be solid (black or red) or merle. Merle coat colour is dominant and germinal reversion has been reported whereby a homozygous merle $(M M)$ Australian shepherd bitch produced homozygous non-merle pups $(\mathrm{mm})$. This has been explained by hypothesising that the merle phenotype is produced by the insertion of transposable gene elements into pigment genes. This gives the dappled white coat colour in the merle animal. It has been suggested that the merle phenotype is analogous to Waardenburg syndrome. ${ }^{74}$ Homozygous merle dogs have been reported as having microphthalmia, microcornea, cornea plana, correctopia, cataract, multiple colobomata and lens abnormalities, as is reported in Waardenburg syndrome. ${ }^{75}$

While heterochromia iridis occurs frequently in the heterozygous merle dog, ocular dysgenesis would appear to occur only in animals homozygous for the merle gene, although some exceptions are said to occur. ${ }^{76} \mathrm{~A}$ series of developmental ocular defects occur in hereditary microphthalmia with colobomata in the Australian shepherd dog. Some of these are related to neural crest abnormalities $^{77}$ and have been shown to be caused by an incompletely penetrant recessive gene. ${ }^{78}$ These merle Australian 
shepherd dogs have a range of defects which include microphthalmia, microcornea, persistent pupillary membranes, heterochromia iridis, dyscoria and correctopia, equatorial staphylomas and cataract. Studies on the embryogenesis of the ocular dysgenesis in this breed have shown that a primary abnormality in the formation of the outer epithelial layer of the optic cup leads to failure of retinal pigment epithelium (RPE) formation. Lacking the support of adjacent RPE, the neural retina in affected areas degenerates. In these areas periocular neural crest fails to differentiate to form choroid and sclera and atypical uveoscleral colobomata occur. ${ }^{76}$

Multiple non-ocular defects such as cleft palate, polydactyly and syndactyly have also been reported in this breed. These may be unconnected with the ocular anomalies, although syndactyly has also been reported in a child with Waardenburg syndrome. ${ }^{79}$ Other neurocristopathic findings such as Hirschsprung syndrome have not been noted with regularity in merle animals. There are many thousands of merle dogs in Britain, but work to examine them ophthalmoscopically in a systematic manner has yet to be attempted. The suggested link between Waardenburg syndrome and the merle trait in dogs is yet another illustration of the potential benefits of forging greater collaboration between the medical and veterinary ophthalmological worlds.

\section{CONCLUSION}

The great advances in our understanding of the involvement and contribution of neural crest in the anterior segment were all made possible because of work on the chick and quail. Even today, little work is undertaken on mammalian models of anterior segment dysgenesis and much extrapolation from basic non-mammalian models is still attempted. Yet in both the pet and the farm animal worlds a number of naturally occurring inherited and non-inherited defects are recognised which might be usefully extrapolated in a comparative context.

It could be argued that the differences between the anterior segment of animals and man negate any attempt to draw lessons from our meagre understanding of abnormalities of the non-primate anterior segment. However, the differences between the eyes of these species underline the lessons which a modern understanding of the anterior segment gives us with regard to goniodysgenesis and associated defects. The further veterinary ophthalmology reaches into the field of congenital ocular defects, the greater could be the benefit for animals and man alike.

Sandra Tatum provided invaluable assistance in obtaining much of the literature cited here. Anthony Moore introduced me to the European Paediatric and Genetic Group where this material was given as a lecture. Jim Bee has constantly fuelled my interest in the neural crest and provided many insights and constructive criticisms of this paper. Financial support is supplied by the Wellcome Trust in the form of a Veterinary Research Training Scholarship.

Key words: Animal model, Anterior segment dysgenesis, Axenfeld's anomaly, Congenital ocular defect, Congenital glaucoma, Goniodysgenesis, Peters' anomaly, Rieger's anomaly.

\section{REFERENCES}

1. Reese AG, Elsworth RM. The anterior chamber cleavage syndrome. Arch Ophthalmol 1966;75:307-18.

2. Waring GO, Rodrigues MM, Laibson PR. Anterior chamber cleavage syndrome: a stepladder classification. Surv Ophthalmol 1975;20:3-27.

3. Townsend WM. Congenital corneal leukomas. I. Central defect in Descemet's membrane. Am J Ophthalmol 1974;77:80-6.

4. Townsend WM, Ramon LF, Zimmerman LE. Congenital corneal leukomas. II. Histopathologic findings in 19 eyes with central defect in Descemet's membrane. Am J Ophthalmol 1974;77:192-206.

5. Townsend WM, Ramon LF, Zimmerman LE. Congenital corneal leukomas. III. Histopathologic findings in 13 eyes with noncentral defect in Descemet's membrane. Am J Ophthalmol 1974; 77:400-12.

6. Kenyon KR. Mesenchymal dysgenesis in Peters' anomaly, sclerocornea and congenital endothelial dystrophy. Exp Eye Res 1975;21:125-42.

7. Treacher Collins E. XI Congenital conditions. Trans Ophthalmol Soc UK 1906;27:203-11.

8. Mann I. Developmental abnormalities of the eye. Philadelphia: JB Lippincott, 1957.

9. Noden DM. An analysis of the migratory behaviour of avian cephalic neural crest cells. Dev Biol 1975;42:106.

10. Johnston MC, Noden DM, Hazelton RD, Coulombre JL, Coulombre AJ. Origins of avian ocular and periocular tissues. Exp Eye Res 1979;29:27-43.

11. Kupfer C, Kaiser Kupfer MI. New hypothesis of developmental anomalies of the anterior chamber associated with glaucoma. Trans Ophthalmol Soc UK 1978;98:213-5.

12. Beauchamp GR, Knepper PA. Role of the neural crest in anterior segment development and disease. J Pediatr Ophthalmol Strabismus 1984;21:209-14.

13. Cook CS, Nowotny AZ, Sulik KK. Fetal alcohol syndrome: eye malformations in a mouse model. Arch Ophthalmol 1987;105:1576-81.

14. Cook CS, Sulik KK. Keratolenticular dysgenesis (Peters' anomaly) as a result of acute embryonic insult during gastrulation. J Pediatr Ophthalmol Strabismus 1988;25:60-6.

15. Shirai S, Ohshika S, Majima A. Ochratoxin A. III. Developmental abnormalities of the anterior segment of the eye induced in mice by ochratoxin A. Acta Soc Ophthalmol Jpn 1985;89:753-60.

16. Shirai S. Eye abnormalities in mouse fetuses caused by simultaneous irradiation of $\mathrm{X}$ rays and ultrasound. Congenital Anomalies 1978;18:269-79.

17. Miller MT, Epstein RJ, Sugar J, Pinchoff BS, Sugar A, Gammon JA, Mittelman D, Dennis RF, Israel J. Anterior segment anomalies associated with fetal alcohol syndrome. J Pediatr Ophthalmol Strabismus 1984;21:8-18.

18. Sulik KK, Johnston MC. Sequence of developmental alterations following acute ethanol exposure in mice: craniofacial features of the fetal alchohol syndrome. Am J Anat 1983;166:257-69.

19. Garcia-Porrero JA, Collado JA, OjedaJL. Cell death during detachment of the lens rudiment from ectoderm in the chick embryo. Anat Rec 1979;193:791-804.

20. Silver J, Hughes AFW. The role of cell death during morphogenesis of the mammalian eye. $\mathbf{J}$ Morphol 1973;140:159-70.

21. Cook CS, Sulik KK. Laminin and fibronectin in retinoidinduced keratolenticular dysgenesis. Invest Ophthalmol Vis Sci 1990;31:751-7.

22. Beauchamp GR. Anterior segment dysgenesis, keratolenticular adhesion and aniridia. J Pediatr Ophthalmol Strabismus 1980;17:55-8.

23. Kilvin JD, Fineman RM, Crandall AS, Olson RJ. Peters' anomaly as a consequence of genetic and nongenetic syndromes. Arch Ophthalmol 1986;104:61-4. 
24. Butler L, Willshaw HE. Ocular and facial maldevelopment: the role of neural crest. Eye 1989;3:64-8.

25. Shields MB, Buckley E, Klintworth GE, Thresher R. Axenfeld Rieger syndrome: a spectrum of developmental disorders. Surv Ophthalmol 1985;29:387-409.

26. Anderson DR. The development of the trabecular meshwork and its abnormality in primary infantile glaucoma. Trans Am Ophthalmol Soc 1981;79:458-85.

27. Remé C, Lalive d'Epinay S. Periods of development of the normal human chamber angle. Doc Ophthalmol 1981; $51: 241-68$

28. Hansson HA, Jerndal T. Scanning electron microscope studies on the development of the iridocorneal angle in human eyes. Invest Ophthalmol Vis Sci 1971;10:252-65.

29. Van Buskirk EM. Clinical implications of iridocorneal angle development. Ophthalmology 1981;88:361-7.

30. Tawara A, Inomata H. Developmental immaturity of the trabecular meshwork in congenital glaucoma. Am J Ophthalmol 1981;92:508-25.

31. Martin CL. Development of the pectinate ligament structure of the dog: study by scanning electron microscopy. Am J Vet Res 1974;35:1433-9.

32. Arnbjerg J, Jensen OA. Spontaneous microphthalmia in two Doberman puppies with anterior chamber cleavage syndrome. J Am Anim Hosp Assoc 1982;18:481-4.

33. Peiffer RL, Fischer CA. Microphthalmia, retinal dysplasia and anterior segment dysgenesis in a litter of Doberman pinschers. J Am Vet Med Assoc 1984;183:875-8.

34. Martin CL, Leopold HW. Aphakia and multiple ocular defects in St Bernard puppies. Vet Med Small Anim Clin 1974;18:448-53.

35. Bergsjo T. Congenital blindness with ocular developmental abnormalities in Doberman Pinscher dogs. J Am Vet Med Assoc 1984; 184:1383.

36. Lewis DG, Kelly DF, Sansom J. Congenital microphthalmia and other developmental ocular anomalies in the Dobermann. J Small Anim Pract 1986;27:559.

37. Shields MB. Axenfeld Rieger syndrome: a theory of mechanism and distinctions from the iridocorneal endothelial syndrome. Trans Am Ophthalmol Soc 1983;81:736-84.

38. Shields MB, Buckley E, Klintworth GE, Thresher R. Axenfeld Rieger syndrome: a spectrum of developmental disorders. Surv Ophthalmol 1985;29:387-409.

39. Sugar HS. Juvenile glaucoma with Axenfeld's syndrome: a histologic report. Am J Ophthalmol 1965;59:1012-9.

40. Alkemade PPH. Dysgenesis mesodermalis of the iris and cornea: a study of Rieger's syndrome and Peters' anomaly. Dissertation, Assen, The Netherlands: Van Gorcum, 1969.

41. Martin CL. Scanning electron microscopic examination of selected canine iridocorneal angle abnormalities. J Am Anim Hosp Assoc 1975;11:300-6.

42. Tesluk GC, Peiffer RL, Brown D. A clinical and pathological study of inherited glaucoma in New Zealand White rabbits. Lab Anim 1982;16:234-9.

43. Brear DR, Insler MS. Axenfeld's syndrome associated with systemic abnormalities. Ann Ophthalmol 1985;17:291-4.

44. Mathis H. Zahnunterzahl und Missbildungen der Iris. $\mathrm{Z}$ Stomatol 1936;34:895-909.

45. Shields MB. Axenfeld Rieger syndrome: a theory of mechanism and distinctions from the iridocorneal endothelial syndrome. Trans Am Ophthalmol Soc 1983;81:736-84.

46. Cross HE, Jorgenson RJ, Levin LS, Kelly TE. The Rieger syndrome: an autosomal dominant disorder with ocular, dental and systemic abnormalities. Perspect Ophthalmol 1979;3:3-16.

47. Mansour AM, Goldberg RB, Wang FM, Shprintzen RJ. Ocular findings in the velo-cardio-facial syndrome. J Pediatr Ophthalmol Strabismus 1987;24:263-6.

48. Carey JC. Spectrum of the DiGeorge syndrome [letter]. J Pediatr 1980;96:955-6.
49. Sulik KK, Cook CS, Webster WS. Teratogens and craniofacial malformation: relationships to cell death. Development 1988;103 Suppl: 213-31.

50. Shields MB. Progressive essential iris atrophy, Chandler's syndrome and the iris nevus (Cogan-Reese) syndrome: a spectrum of disease. Surv Ophthalmol 1979;24:3-20.

51. Rodrigues MM, Phelps CD, Krachmer JH, Cibis GW, Weingeist TA. Glaucoma due to endothelialisation of the anterior chamber angle: a comparison of posterior polymorphous dystrophy of the cornea and Chandler's syndrome. Arch Ophthalmol 1980;98:688-96.

52. Gwin RM, Cunningham DE, Shaver RP. Posterior polymorphous dystrophy of the cornea in cocker spaniels: preliminary clinical and specular microscopic findings. Proc Trans Am Coll Vet Ophthalmol 1983;154-66.

53. Dausche D, Wegner W, Michaelis W. Ophthalmologische Befunde in einer Merlezucht. Dtsch Tierärztl Wochenschr 1977;84:453-92.

54. Dausch D, Wegner W, Michaelis W. Augenveränderungen beim Merlesyndrom des Hundes. Graefes Arch Klin Exp Ophthalmol 1978;206:135-50.

55. Herrmann A, Wegner W. Augenveranderungen bei alteren Tigerteckeln mit essentieller Irisatrophie als zusatzlischem Befund. Praktische Tierarzt 1988;69:33-6.

56. Klinkmann G, Wegner W. Tonometrien bei Merlehunden Dtsch Tierarzt Wochenschr 1987;94:337-8.

57. Klinckmann G, Koniszewski G, Wegner W. Lichtmikroskopische Untersuchungen an den Corneae von merle Dachshunden. Deutsch Tierärztl Wochen 1987;94:338-41.

58. Ritch R, Forbes M, Hetherington J, Harrison R, Podos SM. Congenital ectropion uveae with glaucoma. Ophthalmology 1984;91:326-31.

59. Dowling JL, Albert DM, Nelson LB, Walton DS. Primary glaucoma associated with iridotrabecular dysgenesis and ectropion uveae. Ophthalmology 1985;92:912-21.

60. Wilson ME. Congenital iris ectropion and a new classification for anterior segment dysgenesis. J Pediatr Ophthalmol Strabismus 1990;27:48-55.

61. Cibis GW, Waeltermann JM, Hurst E, Tripathi RC, Richardson W. Congenital pupillary-iris-lens membrane with goniodysgenesis (a new entity). Ophthalmology 1986;93:847-52.

62. Boevé MH, van der Linde-Sipman T, Stades FC. Early morphogenesis of persistent hyperplastic tunica vasculosa lentis and primary vitreous: the dog as an ontogenetic model. Invest Ophthalmol Vis Sci 1988;29:1076-83.

63. Roberts SR, Bistner SI. Persistent pupillary membrane in Basenji dogs. J Am Vet Med Assoc 1968;153:533-42.

64. Burek JD, McElyea U, Fox JG, Stookey JL. Persistent pupillary membranes in a rhesus monkey. J Am Vet Med Assoc 1974;164:719-21.

65. Barnett KC, Knight GC. Persistent pupillary membrane and associated defects in the Basenji. Vet Rec 1969;85:242-9.

66. Bistner S, Rubin LF, Roberts SR. A review of persistent pupillary membranes in the Basenji dog. J Am Anim Hosp 1971;7:143-57.

67. Davidson MG. Congenital cataracts in English cocker spaniels. Vet Rec 1988;122:494

68. Strande A. Nicolaissen B, Bjerkas I. Persistent pupillary membrane and congenital cataracts in a litter of English Cocker spaniels. J Small Anim Pract 1988;29:257-60.

69. Grimes TD. Cataract and other abnormalities in young dogs. $\mathrm{PhD}$ thesis. University College, Dublin, 1976.

70. Schaffer E, Wiesner H, von-Hegel G. Multiple ocular coloboma with persistent pupillary membrane in the snow leopard (Panthera uncia). Tierarzt Prax 1988;16:87-91.

71. Searle AG. Comparative genetics of albinism. Ophthalmic Pediatr Genet $\cdot 1990 ; 11: 159-64$.

72. Gelatt KN, Huston K, Leipold HW. Ocular abnormalities of incomplete albino cattle: ophthalmoscopic examination. Am J Vet Res 1969;30:1313. 
73. Gwin RM, Wyman M, Lim DJ, Ketring K, Werling K. Multiple ocular defects associated with partial albinism and deafness in the dog. J Am Anim Hosp Assoc 1981;17: 401.

74. Dausch D, Wegner W, Franke KD, Flach M. Sinnesverluste bei genetischen Pigmentmangelsyndromen. Dtsch Med Wochenschr 1982;107:1029-32.

75. Klinckmann G, Koniszewski G, Wegner W. Light microscopic investigation of the retinae of dogs carrying the merle factor. J Vet Med 1986;33:674-8.

76. Cook CS, Burling K, Nelson EJ. Embryogenesis of posterior segment colobomas in the Australian Shepherd Dog. Prog Vet Comp Ophthalmol 1991;1:163-70.

77. Gelatt KN, McGill LD. Clinical characteristics of microphthalmia with colobomas of the Australian Shepherd dog. J Am Vet Med Assoc 1972;162:393-6.

78. Gelatt KN, Powell NG, Huston K. Inheritance of microphthalmia with coloboma in the Australian Shepherd Dog. Am J Vet Res 1981;42:1686-90.

79. Zelig S, Deutsch E, Eilon A. Waardenburg syndrome with associated multiple anomalies. J Otorhinolaryngol Rel Spec 1984;46:34-7. 